\title{
Aspectos epidemiológicos da leishmaniose visceral em Teresina-PI, Brasil
}

\author{
Epidemiological aspects of visceral leishmaniosis in Teresina-PI, Brazil
}

Aspectos epidemiológicos de la leishmaniose visceral en Teresina-PI, Brasil

Kelley Christiane Barbosa Silva', Veralice Rosa Soares ${ }^{1}$, Jéssica Larissa Sousa Vaz², Soliane Cristina Rodrigues Costa ${ }^{2}$, Roseane Mara Cardoso Lima Verde ${ }^{3}$, Kécya Patricia Costa Macêdo', Leonardo Ferreira Soares ${ }^{4}$, Joseana Martins Soares de Rodrigues Leitão', Bernardo Melo Neto', Evaldo Hipólito de Oliveira ${ }^{2 *}$.

\section{RESUMO}

Objetivo: Descrever aspectos epidemiológicos da leishmaniose visceral em Teresina-PI no período de 2008 a 2017. Métodos: estudo epidemiológico, observacional e descritivo, com abordagem quantitativa, através de dados secundários de notificações dos casos de LV na cidade de Teresina-PI, no período de 2008 a 2017 , os dados foram coletados no Sistema de Informações de Agravos e Notificação (SINAN) e processados nos programas Microsoft Office e Microsoft Excel 2016 e Tab. para Windows (TabWin) versão 4.14. Resultados: No município de Teresina-PI, a distribuição de casos confirmados de LV manteve-se com flutuação de declínio dos casos notificados. O perfil se constitui pela cor da pele parda, acomete mais o sexo masculino, e pessoas com ou sem escolaridade, enfatiza-se menor incidência ao nível superior, a faixa etária prevalente é de 20 a 39 anos, seguida da faixa de 01 a 04 ano, e faixa de 40 a 59 anos, apresentou casos de pacientes com LV associada a coinfecção com o vírus da Imunodeficiência Humana (HIV). Conclusão: Os aspectos epideomlógicos notificados demostra que Teresina-PI, possui aspectos epidemiológicos endêmica de leishmaniose visceral que precisam ser diagnosticadas e notificadas para reduzir a proliferação da doença.

Palavras-chave: Epidemiologia, Notificação, Leishmaniose visceral.

\begin{abstract}
Objective: to explain the epidemiological aspects of visceral leishmaniasis in Teresina-PI from 2008 to 2017. Methods: Is an epidemiological, observational and descriptive study, with a quantitative approach, through secondary data of reports of Visceral Leishmaniasis in the city of Teresina-PI, from 2008 to 2017, the data were collected in the Information System of Aggravation and Notification (SINAN) and processed in the programs Microsoft Office and Microsoft Excel 2016 and Tab. for Windows (TabWin) version 4.14 . Results: In the municipality of Teresina-PI, the distribution of confirmed LV cases remained with declining fluctuation of reported cases. The profile consisting of brown skin color, affects more males, and people with incomplete schooling, is emphasized lower incidence at the higher level, the prevalent age range is from 20 to 39 years, followed by the range from 01 to 04 year, and age range from 40 to 59 years, presented cases of VL patients associated with coinfection with human immunodeficiency virus (HIV). Conclusion: The reported epidemiological aspects show that Teresina-PI has epidemiological aspects endemic to visceral leishmaniasis that need to be diagnosed and reported to reduce the spread of the disease.
\end{abstract}

Keywords: Epidemiology, Notification, Visceral leishmaniasis.

${ }^{1}$ Centro Universitário Santo Agostinho. Teresina - PI.

2Universidade Federal do Piauí. Teresina - PI. *E-mail: evaldohipolito@gmail.com

3Universidade Brasil. São Paulo - SP.

${ }^{4}$ Universidade Estadual da Paraíba. João Pessoa - PB. 


\section{RESUMEN}

Objetivo: explicar aspectos epidemiológicos de la leishmaniasis visceral en Teresina-PI en el período de 2008 a 2017. Métodos: En el período de 2008 a 2017, se trata de este estudio epidemiológico, observacional y descriptivo, con abordaje cuantitativo, a través de datos secundarios de notificaciones de los casos de Leishmaniosis Visceral (LV) en la ciudad de Teresina-PI, en el período de 2008 a 2017, (en el caso de los programas de Microsoft Office y Microsoft Excel 2016 y Tab. para Windows (TabWin) versión 4.14. Resultados: En el municipio de Teresina-PI, la distribución de casos confirmados de leishmaniasis visceral se mantuvo con fluctuación de declinación de los casos notificados. El perfil que se produce por el color de la piel parda, acomete más el sexo masculino, y personas con escolaridad incompleta, se enfatiza menor incidencia al nivel superior, el rango de edad prevalente es de 20 a 39 años, seguida del rango de 01 años a los 4 años de los pacientes con LV asociada a la coinfección con el virus de la inmunodeficiencia humana (VIH). Conclusión: Los aspectos epideomológicos notificados demuestran que Teresina-PI, tiene aspectos epidemiológicos endémicos de leishmaniasis visceral que se diagnostican y se notifican para reducir la proliferación de la enfermedad.

Palabras clave: Epidemiología, Notificación, Leishmaniasis visceral.

\section{INTRODUÇÃO}

A leishmaniose visceral (LV) é uma doença infecciosa, variável, assintomática, crônica, que acomete várias espécies de mamíferos e destaca-se de diversos tipos, é uma enfermidade transmitida pelo parasita Leishmania, pelo mosquito Lutzomyia longipalpis cuja transmissão da doença urbana, tem como principal reservatório do parasita, o cão, que tem papel importante na transmissão epidemiológica (MARTINS CP, et al., 2018).

No Brasil, a Leishmaniose visceral humana encontra-se nas grandes metrópoles do país, cerca de 71.119 casos notificados desde os anos de 1980 a 2009, com 2.452 casos por ano, com maioria de casos na região Nordeste (LUCENA RV, MEDEIROS JS, 2018). Trata-se de uma das enfermidades tropicais de impacto global, com casos de infecções e morte em países que concentram maior incidência de casos, como o Brasil, com número de notificação menor que a realidade de casos clínicos detectáveis, apresentando quantidade de casos estimados inferiores aos casos notificados (FAUCHER B, PIARROUX F, 2011).

É uma doença transmitida por uma infecção visceral, comuns nas áreas rurais, mas o endemismo da LV tem sido constante nas zonas urbanas. $O$ agente transmissor tem sido encontrado nos ambientes domiciliares urbanos (LUCENA RV, MEDEIROS JS, 2018).

A pessoa infectada pela LV apresenta sintomas como: "febre, hepatoesplenomegalia, linfadenopatia, anemia, hipergamaglobulinemia, edema e estado de debilidade progressivo, podendo levar os pacientes não tratados ao óbito" (LUCENA RV, MEDEIROS JS, 2018). Trata-se de uma doença que deve ser tratada adequadamente, pois os riscos de letalidade quando não tratada pode atingir $90 \%$ dos casos (MARTINS CP, et al., 2018).

Diante do problema epidemiológico da leishmaniose visceral, busca-se aspectos epidemiológicos da leishmaniose visceral no município de Teresina-PI, em razão dos casos notificados e sua influência infecciosa que afeta a população especifica, busca-se identificar a distribuição geográfica de casos confirmados de leishmaniose visceral e ano de notificação em Teresina-PI, bem como, traçar o perfil de casos confirmados de leishmaniose visceral e explanar casos de leishmaniose visceral segundo diagnóstico parasitológico e imunológico, tipo de entrada e evolução clínica.

Relevante para o conhecimento proximal dos aspectos epidemiológicos, o presente estudo visa de trazer reflexões sobre os aspectos epidemiológicos da leishmaniose visceral, diante da expansão da infecção no território Teresinense. Em face das lacunas reais que envolve a leishmaniose visceral, que ainda não alcançou notoriedade e visibilidade necessária para o enfretamento, diagnóstico e tratamento dos casos. 


\section{MÉTODOS}

Trata-se de um estudo epidemiológico, observacional e descritivo, com abordagem quantitativa e retrospectiva, usando dados secundários do Sistema de Informações de Agravos e Notificação (SINAN), referente às notificações de casos de Leishmaniose Visceral (LV) na cidade de Teresina-PI, delimitada em um período de 10 anos (2008 a 2017).

A área de estudo se constitui de uma população estimada em 861.442 mil habitantes e uma área de $584,94 \mathrm{hab} / \mathrm{km}^{2}$, sendo a capital do Estado e cidade mais povoada. Localizada na região meio-norte do Piauí em uma faixa de transição entre o semiárido Nordestino e a região Amazônica, estando a $350 \mathrm{~km}$ de distância do litoral. Possui zona de baixa latitude e nos limites da área semiárida do Nordeste brasileiro, o município apresenta clima tropical e subtropical dos mais quentes do país (PREFEITURA DE TERESINA, 2010; IBGE, 2017).

Foram estudadas as seguintes variáveis para Leishmaniose Visceral (LV): ano do diagnóstico, município de notificação, raça, zona de residência, sexo, faixa etária, escolaridade, coinfecção HIV, critério de confirmação, diagnóstico parasitológico e imunológico, tipo de entrada e evolução clínica.

O mapa de saúde, tabelas e gráficos foram calculados através de frequências absolutas e percentuais, sendo processados nos programas Microsoft Office e Microsoft Excel 2016 e Tab para Windows (TabWin) versão 4.14. A população residente do município em estudo utilizada nos cálculos dos índices de incidência e mortalidade foi obtida nos bancos de dados do IBGE e suas projeções. Devido a utilização somente de dados secundários, não houve necessidade de apreciação em Comitê de Ética em Pesquisa (CEP), estando de acordo com a Resolução de número 466 de 12 de dezembro de 2012 do Conselho Nacional de Saúde.

\section{RESULTADOS E DISCUSSÃO}

Da totalidade de casos notificados no Estado do Piauí, conforme a FIGURA 01, a capital Teresina representa o maior número com 1.683 casos notificados (77,48\% do total), seguido de Parnaíba com 112 casos (5,15\% do total), Floriano com 65 casos (2,99\% do total) e Miguel Alves com 43 casos (1,98\% do total).

Destaca-se ainda, que as áreas de maior probabilidade de infecção favoráveis à proliferação do vetor, relaciona-se a precárias condições de infraestrutura sanitária, criação de animais, condições climáticas, cobertura vegetal com predomínio de árvores frutíferas, crescimento desordenado de áreas, acúmulo da matéria orgânica, além disso, existe uma grande incidência de doenças como a sobre a $L V$ na região Nordeste (MARTINS CP, et al., 2018).

A leishmaniose visceral é uma doença crônica causada por protozoário do gênero Leishmania, constituise como um problema de saúde pública no Brasil, principalmente na região Nordeste (SOUSA NA, et al., 2018).

No período de 2008 a 2017, foram notificados no Estado do Piauí um total acumulado de 2.172 casos, no Sistema de Informação de Agravos de Notificação (SINAN). De acordo com o mapa de saúde a distribuição demográfica dos casos confirmados e notificados no Estado do Piauí, na Figura 1 demonstra.

A expansão da doença nessas regiões, estão associadas aos baixos índices de desenvolvimento, adaptação ambiental do vetor da LV nos locais modificados pelo homem, redução ou falha nas ações de controle na saúde e educação, favorecendo a disseminação epidemiológica (CAVALCANTE IJM, VALE MR, 2014).

A LV no Estado do Piauí é registrada desde 1934, relaciona-se as condições climáticas da região que tem maiores índices da doença (SANTOS GM, et al., 2017).

Diante dessa constatação, pode-se perceber que Teresina possui maior incidência da doença, por conter aspectos vulneráveis a peculiaridades epidemiológicas, para que o vetor da LV se estabeleça com um grave problema de saúde pública. A respeito da notificação por período específico, o Gráfico 1 apresenta. 
Figura 1 - Distribuição geográfica de casos confirmados de leishmaniose visceral segundo município de notificação em Teresina-PI, no período de 2008 a 2017.

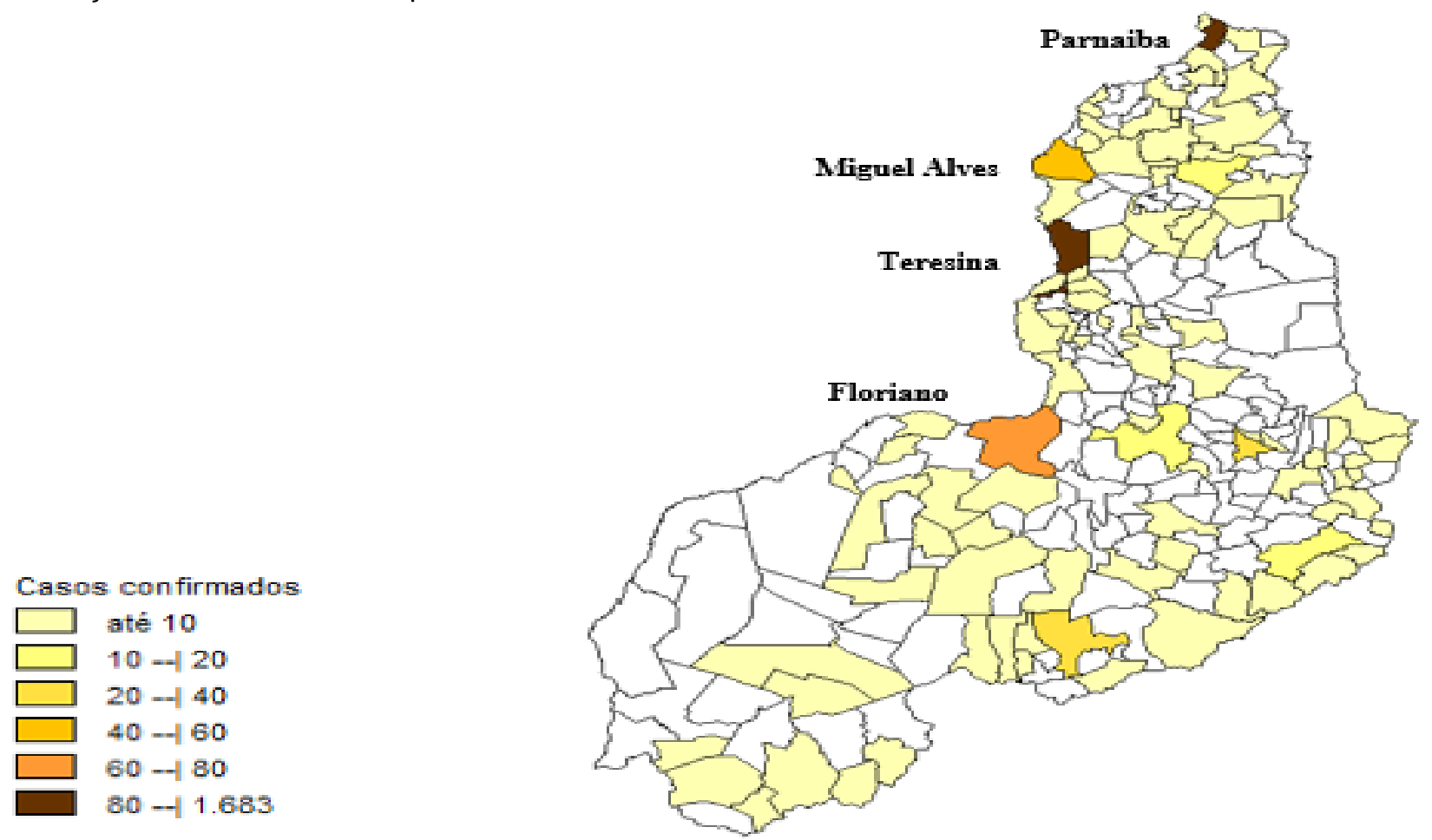

Fonte: Silva KCB, et al., 2020. Baseado em: Ministério da Saúde/SVS - Sistema de Informação de Agravos de Notificação - SINAN Net, 2019.

Gráfico 1 - Total de casos confirmados de leishmaniose visceral segundo ano de notificação em Teresina-PI, no período de 2008 a 2017.

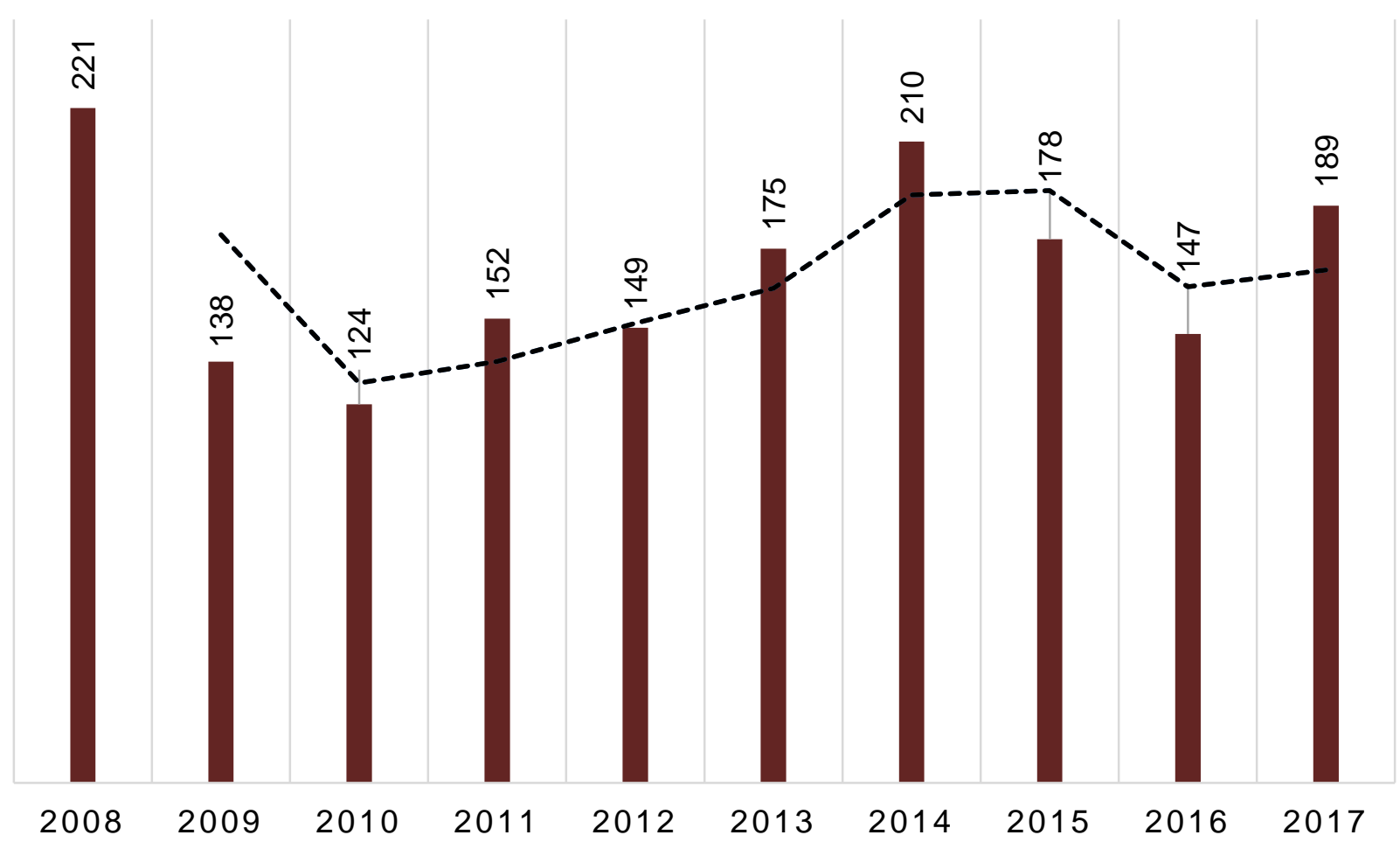

Fonte: Silva KCB, et al., 2020. Baseado em: Ministério da Saúde/SVS - Sistema de Informação de Agravos de Notificação - SINAN Net, 2019. 
O Gráfico 1, representa a distribuição de casos confirmados de leishmaniose visceral nos anos analisados, no município de Teresina. Pode-se observar uma flutuação entre declínio e elevação, sendo 2008 (221 casos) e 2014 ( 210 casos) os anos de maior prevalência, representando 13,13\% e 12,47\% do total, respectivamente. Em relação a taxa de incidência de LV na população de Teresina, observa-se que em 2008 essa taxa era de 27,14 casos/100.000 habitantes e decaiu para 21,94 casos/100.000 habitantes em 2017. A menor incidência ocorreu no ano de 2010 com 124 casos notificados, que representa 7,36\%.

Em face a possibilidade de redução de casos refuta em condições de saúde geradoras de controle, monitoramento e informações à população, que indicam a redução dos aspectos epidemiológicos que acarretam a saúde, fornecendo o embasamento necessário ao grau de incerteza da doença e das providências cabíveis para sua redução (MARTINS CP, et al., 2018). A respeito do perfil dos casos de leishmaniose visceral, na Tabela 1 a seguir explana.

Tabela 1 - Distribuição de casos confirmados de leishmaniose visceral segundo raça, zona de residência, sexo, escolaridade e faixa etária em Teresina-PI, no período de 2008 a 2017.

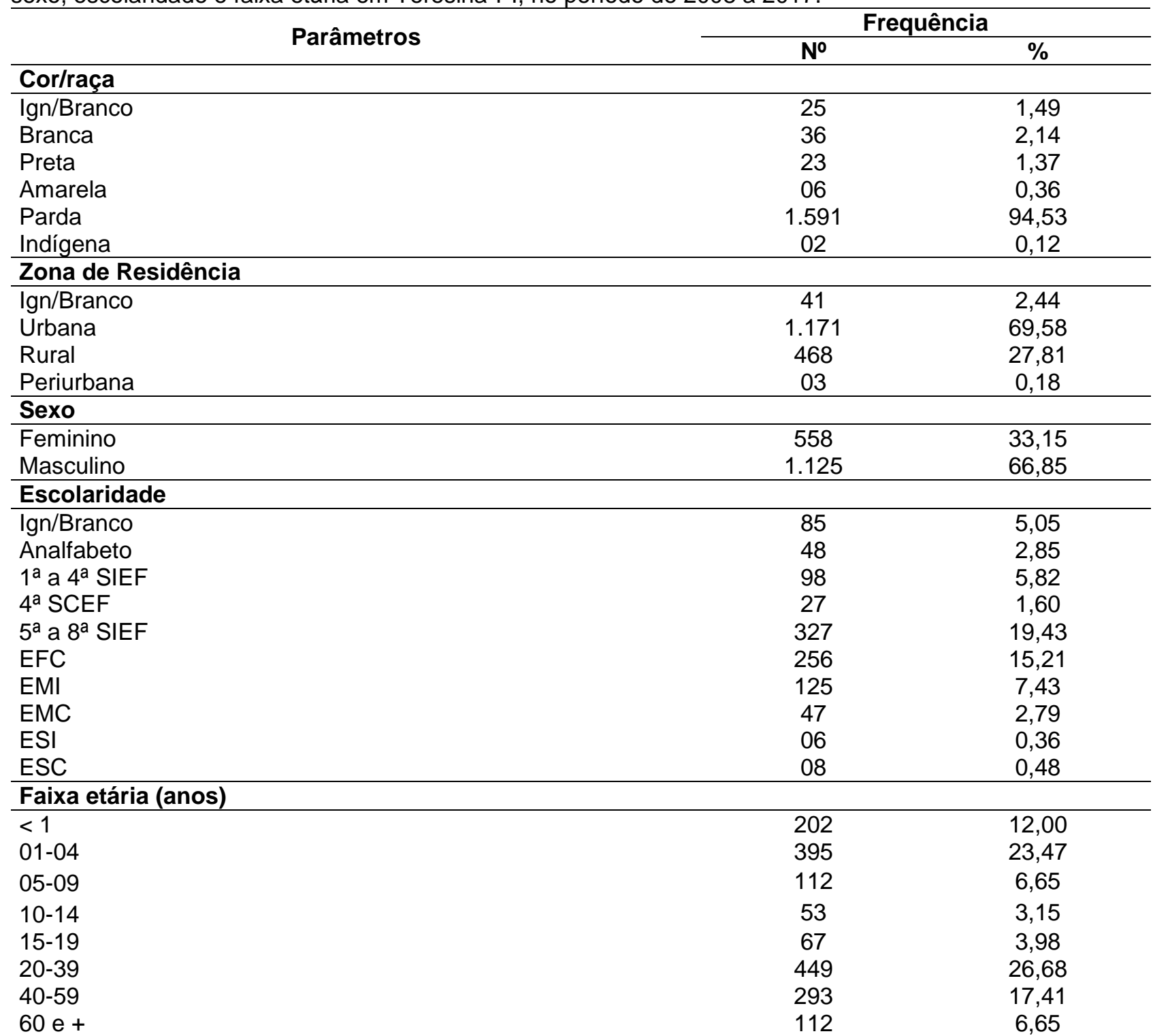

Legenda: Ign/Branco = ignorado ou branco; $\operatorname{SIEF}=$ série incompleta do ensino fundamental; SCEF = série completa do ensino fundamental; $\mathrm{EFC}$ = ensino fundamental completo; $\mathrm{EMI}=$ ensino médio incompleto; EMC = ensino médio completo; $\mathrm{ESI}=$ ensino superior incompleto; $\mathrm{ESC}=$ ensino superior completo.

Fonte: Silva KCB, et al., 2020. Baseado em: Ministério da Saúde/SVS - Sistema de Informação de Agravos de Notificação - SINAN Net, 2019. 
A Tabela 1, agrupa os resultados dos aspectos epidemiológicos do total de casos confirmados de leishmaniose visceral no período em análise, foram utilizadas as variáveis raça, zona de residência, sexo, escolaridade e faixa etária.

Dessa maneira, observa-se que $94,53 \%$ do total de pessoas possui a cor da pele parda, branca $(2,14 \%)$ e preta com $1,37 \%$, com a maior parte residente da zona urbana ( $69,58 \%$ do total), porém $27,81 \%$ dos casos notificados tinham moradia na zona rural.

Adicionalmente, a doença é prevalente no sexo masculino $(66,85 \%)$ que possui escolaridade incompleta da $5^{\underline{a}}$ a $8^{a}$ série do ensino fundamental $(19,43 \%$ do total), seguida de ensino fundamental completo $(15,21 \%)$ e ensino médio incompleto $(7,43 \%)$.

Vale ressaltar, que ao longo do período analisado houve a ocorrência da LV em 08 casos de pacientes com ensino superior completo. A patologia foi prevalente na faixa de 20 a 39 anos, representando $26,68 \%$ do total, seguida da faixa de 01 a 04 anos $(23,47 \%)$ e ainda, $17,41 \%$ para a faixa de 40 a 59 anos. Ademais, foi observado a 202 casos em crianças abaixo de um ano de idade (12,00\%), demonstrando ser uma quantidade significativa.

Foram notificados 242 casos de pacientes com LV associada a coinfecção com o vírus da imunodeficiência humana (HIV), que correspondem a $14,37 \%$ do total de casos registrados na capital.

A respeito da coinfecção HIV / Leishmania, apresenta-se um prognóstico mais sombrio presente em casos de imunodeficiência grave: de CD4 inferior a 200 por microlitro em $90 \%$ dos casos, que merece atenção especial, a coinfecção, também corresponde a um círculo vicioso lesões bronquiais, digestivas ou tegumentares incomuns aparecem com mais frequência, a presença de outros sintomas, dificulta 0 diagnóstico, sem necessariamente estar relacionada à parasitose (FAUCHER B, PIARROUX F, 2011).

A LV é uma doença crônica e sistêmica, clinicamente pode ser caracterizada por sintomas decorrentes que precisam ser tratadas, com febre, perda de peso, astenia, anemia, acomete indivíduos e atinge taxas de mortalidade em crianças desnutridas e pessoas infectadas pelo vírus HIV (CAVALCANTE IJM, VALE MR 2014).

Salienta-se que em 12,24\% das notificações essa informação foi ignorada e que 1.235 casos não apresentaram a LV associada. Portanto, destaca-se que o diagnóstico da leishmaniose visceral, não é identificada precisamente na admissão, muitas vezes, é confundida com hemopatia ou tecido conjuntivo (FAUCHER B, PIARROUX F, 2011).

Essa dificuldade de diagnóstico se dá pela semelhança que a LV tem com algumas doenças associadas a bacteriose septicêmica prolongada, ao quadro clínico de doenças linfoproliferativas e com a esquistossomose mansônica (SOUZA MA, et al., 2011).

Embora o critério laboratorial tenha correspondido ao critério de confirmação mais utilizado para o diagnóstico da LV, nesse estudo houve um percentual de não realização de testes laboratoriais para o diagnóstico. Nos casos humanos, essa investigação é rotineiramente realizada com base em parâmetros clínicos e epidemiológicos (SANTOS GM, et al., 2017).

Destaca-se que o número de casos de LV, quanto a sua evolução são ignorados, quando se trata do perfil, da qualidade dos registros Sistemas de Informação, que são limitados e dificultam "a realização de estudos epidemiológicos sobre os problemas de saúde da população" (MAIA HAAS, et al., 2018).

De tal forma, é importante a confirmação dos casos, através de métodos clínicos associados, para uma construção diagnóstica, métodos parasitológicos, sorológico (SOUZA MA, et al., 2011).

Assim, o SINAN apresenta como critérios baseados em aspectos clínico-epidemiológicos os exames parasitológico e imunológico, ambos baseados em aspectos laboratoriais. Para a confirmação do diagnóstico dos casos de leishmaniose visceral em Teresina, a Tabela 2 explana. 
Tabela 2 - Casos confirmados de leishmaniose visceral segundo diagnóstico parasitológico e imunológico em Teresina-PI, no período de 2008 a 2017.

\begin{tabular}{lcccc}
\hline & \multicolumn{2}{c}{ Parasitológico } & \multicolumn{2}{c}{ Imunológico (IFI) } \\
\cline { 2 - 5 } & $\mathbf{n}$ & $\%$ & $\mathbf{n}$ & $\%$ \\
\hline Ign/Branco & 79 & 0,21 & 79 & 0,21 \\
Positivo & 945 & 27,78 & 227 & 49,79 \\
Negativo & 385 & 3,91 & 158 & 16,46 \\
Não realizado & 274 & 68,11 & 1.219 & 33,54
\end{tabular}

Legenda: $\operatorname{lgn} /$ Branco = ignorado ou branco; IFI = Teste de imunofluorescência indireta.

Fonte: Silva KCB, et al., 2020. Baseado em: Ministério da Saúde/SVS - Sistema de Informação de Agravos de Notificação - SINAN Net, 2019.

De acordo com a Tabela 2, representada por $89,54 \%$ dos casos registrados. Portanto, do total de casos analisados 945 (27,78\% do total) deram positivo para o exame parasitológico e 227 casos $(49,79 \%$ do total) para o teste imunológico. Ademais nos dois resultados o número de casos ignorados/branco foi de $0,21 \%$. Como os critérios são baseados em aspectos clínico-epidemiológicos os exames parasitológico e imunológico, ambos baseados em aspectos laboratoriais dos casos confirmados, verifica-se no Gráfico 20 tipo de entrada.

Gráfico 2 - Distribuição de casos confirmados de leishmaniose visceral conforme o tipo de entrada em Teresina-PI, no período de 2008 a 2017.

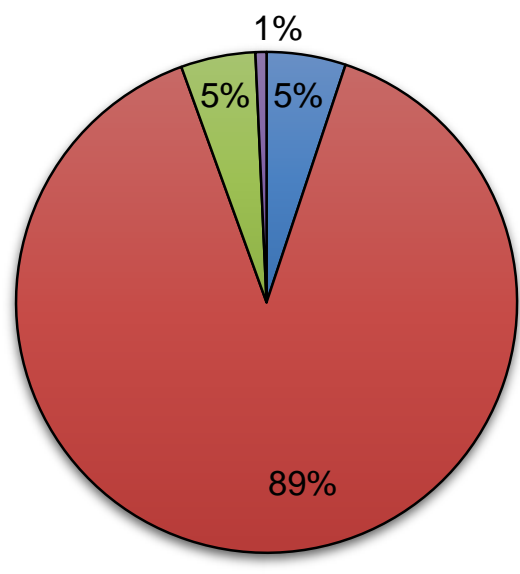

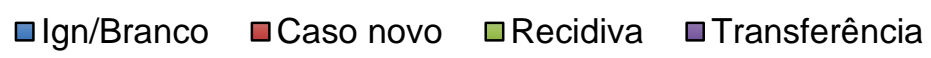

Legenda: Ign/Branco = ignorado ou branco.

Fonte: Silva KCB, et al., 2020. Baseado em: Ministério da Saúde/SVS - Sistema de Informação de Agravos de Notificação - SINAN Net, 2019.

No Gráfico 2 é possível notar a grande proporção de casos novos notificados entre os anos de 2008 e 2017, que correspondem a $89 \%$ dos casos (1.504 casos) novos registrados no Estado. Adicionalmente, a porcentagem de recidivas e casos ignorados representaram $5 \%$, enquanto as transferências são apenas $1 \%$ do total (12 casos), 10 ocorrências, $2 \%$ do total de notificações. Nesse sentido, o diagnóstico para a evidência do parasita necessita de amostras profundas que ofereçam sensibilidade para a identificação e notificação (FAUCHER B, PIARROUX F, 2011).

De tal forma, observa-se que no município de Teresina-PI houve um significativo crescimento de casos notificados de LV novo, que traz como referência positiva para a possibilidade de tratamento adequando aos casos subnotificados. Entretanto, abre-se uma lacuna, quando se trata da proliferação da doença e respectivamente dos vetores, em razão do grande número de casos novos. 
O aparecimento de novos focos de LV nas áreas endêmicas, tiveram a contribuição de diversos fatores: em decorrência do processo de urbanização, intensa migração, transformações ambientais, pauperização, mudanças econômicas ou sociais, a LV, passou a fazer parte da realidade dos grandes centros urbanos (SOUSA NA, et al., 2018). A confirmação da doença por tipo de entrada confirmados no Gráfico 3, representa:

Gráfico 3 - Casos confirmados de leishmaniose visceral por tipo de entrada em Teresina-PI, no período de 2008 a 2017.

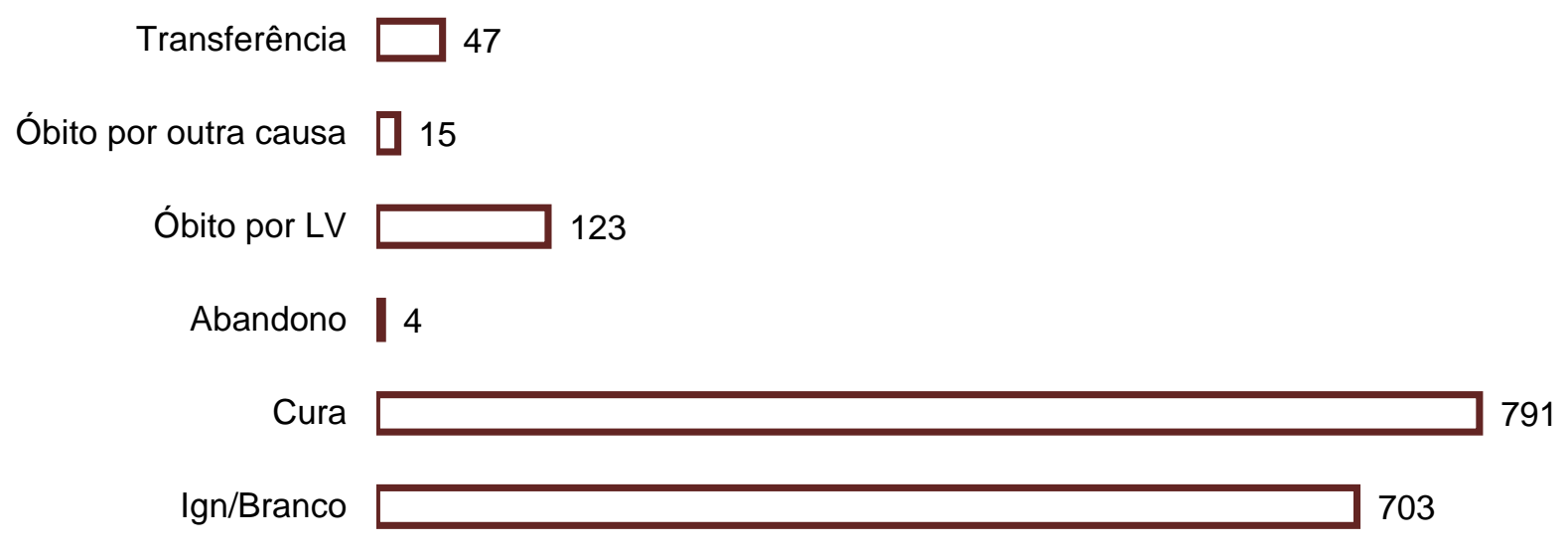

Fonte: Silva KCB, et al., 2020. Baseado em: Ministério da Saúde/SVS - Sistema de Informação de Agravos de Notificação - SINAN Net, 2019.

O Gráfico 3 apresenta os casos confirmados de LV por tipo de entrada, onde 791 casos $(47,00 \%)$ cursaram com a cura, todavia, 703 casos $(41,77 \%)$ foram ignorados, uma quantidade significativa. Para os casos de óbito, identificou-se que $7,30 \%$ das foram por LV, e apenas 0,89\% óbitos por outras causas. Ademais, os casos de transferências foram maiores que o de abandono, 2,79\% e 0,23\%, respectivamente.

Quando se trata dos critérios de cura, trata de dar respostas clinicas aos primeiros sinais da doença, melhorando o estado geral do paciente, mesmo que a regressão da doença, por meio do tratamento dure alguns meses, considerando a evolução clínica, controle parasitológico favoráveis, devendo avalia-los por meio de análise univariada, as condições e os fatores clínicos e laboratoriais para evitar riscos de evolução para o óbito (BRASIL, 2011).

Diante dos dados apresentados no Gráfico 3, percebe-se que quase $50 \%$ dos casos foram ignorados, e isso revela a necessidade de reforças medidas direcionadas a contração da LV e diagnóstico, para acentuar níveis de redução da doença, é preciso a notificação e investigação de casos seja objeto de informações e análise de região, perfis e distribuição, para que os níveis de intervenção municipal, estadual e federal possa contribuir para a redução dessa epidemiologia (SOUSA NA, et al., 2018).

Nota-se que LV representa um grande problema de Saúde Pública e merece destaque epidemiológico devido a diversidade de aspectos clínicos, principalmente lesões desfigurantes e incapacitantes (ROCHA TJM, et al., 2015).

A LV em pacientes não tratados, a evolução pode ser rápida, ao assumir caráter crônico, progride e aumenta a suscetibilidade às infecções secundárias podendo atingir altos níveis de mortalidade (SOUZA MA, et al., 2011).

As medidas de prevenção e controle do vetor devem fazer parte das ações de vigilância em saúde de acordo com cada situação e características epidemiológicas e entomológicas local, as propostas e recomendações devem ser voltadas para o manejo ambiental, entre outras ações, fazer o controle vetorial e dos reservatórios. No sentido de otimizar o controle do vetor e vigilância da LV, torna-se relevante investigar e delimitar os focos e sobretudo, agir a partir do primeiro caso canino, examinar no raio mínimo de 100 cães 
da área, por meio de busca ativa, coleta de amostras por exame parasitológico da espécie de Leishmania (BRASIL, 2016).

Além das medidas voltadas para o controle do vetor, deve-se considerar a proteção individual da população humana, em razão da exposição e contato com o mosquito vetor, para isso, pode usar telas nas portas e janelas, mosquiteiros, repelentes. O controle da LV necessita de medidas permanentes para manter o ambiente urbano e doméstico favorável para evitar ou reduzir a proliferação do vetor (BRASIL, 2006).

É preciso manter o ambiente limpo, dirigir ações de prevenção com limpeza urbana, manejo e saneamento ambiental, eliminação e destino adequado dos resíduos sólidos orgânicos, umidade e animais domésticos dentro de casa contribuindo para redução do problema, diante dos indicadores de letalidade e transmissão (BRASIL, 2006).

\section{CONSIDERAÇÕES FINAIS}

Do exposto, os dados apresentados demonstraram que a distribuição de casos confirmados de leishmaniose visceral no município de Teresina de 2008 a 2017, houve flutuação de declínio em 2008, com 27,14 casos/100.000 habitantes decaindo para 21,94 casos/100.000 habitantes em 2017, nos casos confirmados o perfil apresentou variáveis quanto a raça a maioria $(94,53 \%)$ na cor parda, zona de residência prevalece $69,58 \%$ do total na zona urbana, e $27,81 \%$ na zona rural, acomete mais pessoas do sexo masculino, com escolaridade incompleta do ensino fundamental e médio, faixa etária de 20 a 39 anos com $26,68 \%$ dos casos, seguindo de crianças abaixo de 1 ano com $12 \%$, casos de pacientes com LV associada a coinfecção com o vírus da imunodeficiência humana (HIV) notificados, casos positivos para o exame parasitológico para o teste imunológico, crescente na entrada com casos novos de LV, $47,00 \%$ cursaram com a cura, todavia, $41,77 \%$ foram ignorados, $7,30 \%$ chegaram a óbito, casos de transferências maiores que o de abandono respectivamente. Contudo, em Teresina-PI há expressiva vigência epidemiológica de LV relacionada aos fatores ambientais para o vetor com evidência de novos casos.

\section{REFERÊNCIAS}

1. BRASIL. Ministério da Saúde. Secretaria de Vigilância em Saúde. Departamento de Vigilância Epidemiológica. Manual de vigilância e controle da leishmaniose visceral / Ministério da Saúde, Secretaria de Vigilância em Saúde. Departamento de Vigilância Epidemiológica. - Brasília: Editora do Ministério da Saúde, 2006.120 p.: il. color - (Série A. Normas e Manuais Técnicos).

2. BRASIL. Ministério da Saúde. Secretaria de Vigilância em Saúde. Departamento de Vigilância Epidemiológica. Leishmaniose visceral: recomendações clínicas para redução da letalidade / Ministério da Saúde. Secretaria de Vigilância em Saúde. Departamento de Vigilância Epidemiológica. - Brasília: Ministério da Saúde, 2011.78 p.: il. (Série A. Normas e Manuais Técnicos).

3. BRASIL. Ministério da Saúde. Secretaria de Vigilância em Saúde. Coordenação-Geral de Desenvolvimento da Epidemiologia em Serviços. Guia de Vigilância em Saúde: [recurso eletrônico] / Ministério da Saúde, Secretaria de Vigilância em Saúde, Coordenação Geral de Desenvolvimento da Epidemiologia e Serviços. - 1. ed. atual. - Brasília: Ministério da Saúde, 2016. 773 p.

4. CAVALCANTE IJM, VALE MR. Aspectos epidemiológicos da leishmaniose visceral (Calazar) no Ceará no período de 2007 a 2011. Rev Bras Epidemol, out-dez 2014.

5. FAUCHER B, PIARROUX F. Actualités sur les leishmanioses viscérales. Visceral leishmaniasis: An Update La Revue de médecine interne, 2011. p 544-551.

6. IBGE - Instituto Brasileiro de Geografia e Estatística. População no último censo. 2017.

7. LUCENA RV, MEDEIROS JS. Caracterização epidemiológica da leishmaniose visceral humana no nordeste brasileiro entre 2010 e. 2017. Jornal of Biology \& Pharmacy and Agricultural Management, v. 14, n. 4, out/dez 2018. ISSN 19834209.

8. MAIA HAAS, et al. Perfil epidemiológico dos casos de leishmaniose visceral em feira de santana, bahia, no período de 2001 A 2015. Rev. Saúde Col. UEFS, Feira de Santana, 2018; 8: 70-74.

9. MARTINS CP, et al. Monitoramento epidemiológico como Instrumento de apoio à gestão de saúde: análise das notificações de leishmaniose visceral em Sobral, Ceará. Rev. Adm. Saúde - 2018; 18(72). 
10. PREFEITURA DE TERESINA. Perfil de Teresina: Econômico, social, físico e demográfico. Secretaria Municipal de Desenvolvimento Econômico e Turismo. 2010.

11. ROCHA TJM, et al. Aspectos epidemiológicos dos casos humanos confirmados de leishmaniose tegumentar americana no Estado de Alagoas, Brasil. Rev Pan-Amaz Saude; 2015; 6(4).

12. SANTOS GM, et al. Aspectos Epidemiológicos e Clínicos da Leishmaniose Visceral no Estado do Piauí, Brasil. Revista Eletrônica da FAINOR, Vitória da Conquista, 2017; 10(2): 142-153.

13. SINAN, Sistema de Informação de Agravos de Notificação. Ministério da Saúde/SVS - SINAN Net, 2019.

14. SOUSA NA, et al. Perfil epidemiológico dos casos de leishmaniose visceral em Sobral-CE. de 2011 a 2015. SANARE, Sobral - v.17, n.01, p.51-57, jan. /Jun. - 2018.

15. SOUZA MA, et al. Leishmaniose Visceral humana: do Diagnóstico ao Tratamento. 2011. 